Parasitic puzzles

\section{Sydney Cohen}

Living Together: The Biology of Animal Parasitism. By William Trager. Plenum: 1986. Pp.467. \$71.40.

WILliam Trager has been a dedicated student of animal parasitism throughout his 50 years on the staff of the Rockefeller Institute in New York. During most of that time the subject was a relatively neglected one. The simpler prokaryote parasites and their host interactions are more amenable to study and received much greater attention. The recent surge of interest in animal parasitism reflects an increased awareness of the global impact of animal parasites as human pathogens, but stems also from several technological advances which have transformed the feasibility of carrying out experiments in the subject. Among such advances is Trager's own most notable scientific achievement, with Jensen in 1976, of cultivating for the first time the human malaria parasite, Plasmodium falciparum.

Animal parasites are extraordinarily complex and adaptable organisms. During successive life cycles in different host species, individual parasites may assume forms so disparate as to have been originally regarded as separate species. Alternating life cycles may also involve abrupt changes in metabolism, such as the switch from the glycerophosphate oxidase system of the bloodstream form of African trypanosomes to the cytochromemediated respiration of the insect form which is non-infective for its mammalian host. The study of animal parasitism is therefore basically an attempt to understand the sequential control of gene expression which generates alternative parasite forms adapted to recognition, penetration, growth and reproduction in hosts as different as (for example) the sandfly and man. In addition, the student of animal parasitism must attempt to delineate the complex reactions of the host to invasive challenge.

In confronting this daunting task, Trager deals first with a series of fundamental biological events. He starts with parasite recognition and entry into the host, and their attachment to and penetration of specific host tissues and cells. There follows a discussion of the interface between host and parasite and the molecular exchanges across these surfaces that are vital for parasite survival. Host reactions to parasite invasion are considered in relation to innate immunity, the important and often mysterious role of the spleen, acquired immunity and the pathogenesis of parasitic disease. In the latter part of the book, phenomena of parasitism are discussed in relation to a selection of specific protozoan and helminthic parasites of human beings and other vertebrates that are currently the centre of research work. The closing chapters deal briefly with symbiosis and with the methods traditionally used for the control of parasitic diseases, namely, chemotherapy and ecological methods such as vector control.

Throughout the text, Trager draws attention to the innumerable questions raised by the phenomena he describes. In a few instances these can be satisfactorily accounted for in molecular terms. For example, we at last have an answer to the long-standing puzzle of why West Africans and their descendants in the New World are totally refractory to infection with Plasmodium vivax and yet are susceptible to the other plasmodial species that infect mankind. Also, the means whereby the sickle-cell gene engenders resistance to infection by malignant tertian malaria is understood in detail. A great deal is also known about the structural and can trypanosomes which mediates their evasion of potentially lethal immune attack by the mammalian host. For the most part, however, the biological phenomena described by Dr Trager with arresting simplicity provide a Pandora's box of genetic basis of antigenic variation in Afri-

puzzles which will stimulate and challenge future generations of molecular pathologists. The answers - when they come will illuminate not only the mechanisms of animal parasitism but also our understanding of biological differentiation.

In his introduction to the book, Joshua Lederberg remarks that descriptions of the lives and adaptations of animal parasites are "a veritable Arabian nights of narrative, not of the human imagination, but of Nature's". The subject is indeed a fascinating one, and also is of great consequence in human health and welfare. This book, distilled from a lifetime's work, and set out in uncluttered style with abundant illustrations, will be read with profit and enjoyment by a wide audience including both aspiring and established molecular parasitologists. During the past decade many imaginative initiatives have transformed the study of animal parasitism by bringing together research workers from a variety of disciplines. Dr Trager's book will give further impetus to recruitment into this engrossing and important area of research.

Sydney Cohen is Emeritus Professor of Chemical Pathology in the United Medical and Dental Schools of Guy's and St Thomas's Hospitals, London SEI TEH, UK.

\section{Unsure accuracy}

\section{Alan J. Charig}

The Riddle of the Dinosaur. By John Noble Wilford. Faber \& Faber/Knopf: 1986. Pp.304. £14.95, \$22.95.

ONE might assume from the title that this is just another book on dinosaurs; after all, there are already so many on the market that thinking up a new title must always be a problem. But the exact wording hints strongly at the distinctive nature of this excellent volume. For it is not a descriptive work, listing the various genera of dinosaur and giving an account of the anatomy, physiology and habits of each, nor is it even concerned with their evolutionary history; rather does it deal with the history of dinosaur discovery, with dinosaur research and with the many controversies (both past and present) that bedevil the life of the dinosaurologist.

The text has been well researched and is factually correct. It is also stylishly written, and is interesting, even to the professional dinosaur worker. Most important of all, it reports on the controversies in a balanced, impartial manner, often coming to no positive conclusions but leaving the reader sitting on the fence - which. in our present state of knowledge, is in many cases the proper place to be.

The author has based much of his book on interviews and discussions with well- known scientists active in the dinosaur field. Since he himself is an American, a Pulitzer Prize-winning science correspondent for The New York Times, it is understandable that those people he chose to talk to were all from the United States; the book therefore gives the impression that dinosaurology today is an almost exclusively American subject. His historical perspective nevertheless embraces a fair amount of material from outside North America; it includes - as it must - the story of the first discovery of dinosaur retion, by Mantell and subsequently Cuvier, that reptiles of enormous size and (as originally conceived) herbivorous diet had existed in Mesozoic times.

My only complaints are to do with the illustrations, which are extremely few. One of them, the family tree on p. 189 , is familiar; I recognize it from another volume, although its source is nowhere acknowledged. In the middle of the book are seven colour restorations by Douglas Henderson; his dinosaurs look wooden and his pictures as a whole have neither scientific nor aesthetic appeal. Moreover three of the seven are given the wrong date.

That notwithstanding. here is a book that no dinosaur addict - be he a professional or one of those innumerable keen amateurs - can afford to be without.

Alan J. Charig is in the Department of Palaeontology, British Museum (Natural History), Cromwell Road, London SW7 $5 B D$, UK. mains, in England, and the initial percep- 